\title{
Strategy of Persuation in the Printed Public Advertisements
}

\section{인쇄공익광고에 나타난 설득 전략으로서의 종결 표현 연구}

Jung-mi Jeon ${ }^{1}$

전정미 ${ }^{1}$

${ }^{1}$ Professor, Korean Language \& Litereture Department, Sang Myung University, S. Korea, meejeon@smu.ac.kr

\begin{abstract}
The main purpose of this study is to analyze the final ending forms in the headlines of printed public advertisements and to determine what aspects of the expressions appear when communicating instructive messages to members of society for the public interest. To this end, 178 printed public advertisements containing 10 sub-themes belonging to the main theme of 'social community' were analyzed. The results indicated that in the headings of printed public advertisements sentences containing final ending forms were more frequently used (74.16\%) than sentences without the ending forms like slogans $(25.84 \%)$ in delivering the intended public message. In addition, among the final ending forms, narrative forms were more favored (71.97\%) than interrogative(19.7\%) and imperative $(8.33 \%)$ forms, suggesting that narrative statements that simply describes the facts have been dominantly used as a strategy of persuasion than strong command or instruction in order to weaken the impression of being forced from the hearer's perspective. This phenomenon can be interpreted as strategic use of language to achieve the common purpose of public advertisement and to induce voluntary participation of the members through encouraging or simply raising issues rather than authoritative, unilateral instruction by expressing deference for the members of the society who is also hearers of the advertisement.
\end{abstract}

Keywords: Printed Public Service Advertisement, Headlines, Persuasion Strategy, Final Ending Form

요약: 이 연구의 목적은 인쇄 공익광고 표제문에 나타난 종결 표현을 분석하여, 공익을 위해 사회 구성원에게 지시적 메시지를 전달할 때 어떤 양상이 나타나는지 살펴보는 것 이다. 이를 위해 '사회공동체' 라는 대주제의 하위유형으로, 10 개의 소주제를 담고 있 는 인쇄 공익광고 178 편의 분포와 특징을 분석하였다. 그 결과, 인쇄 공익광고의 표제문 은 메시지를 전달할 때, 종결어미가 포함된 경우가 132 편(74.16\%)으로 나타나, 표어와 같이 비종결형으로 표현되는 경우 $(25.84 \%)$ 보다 높은 빈도를 보인다. 또한 종결형 중에서 도 서술형 $(71.97 \%)$, 의문형(19.7\%), 명령형(8.33\%)의 순으로 나타나, 공익을 위한 설득 전략으로 서술문을 사용하는 '강제성의 약화' 전략이 사용되고 있음을 확인하였다. 이와 같은 현상은 공익광고의 목적이 비록 공공의 이익을 위한 것이지만 청자가 되는 구성원 의 입장을 배려하여 메시지를 전달하는 것이며, 일방적인 지시가 아니라 권유나 문제 제 기를 통한 구성원의 자발적 참여를 유도하기 위한 것임을 확인하였다.

Received: June 19, 2021; $1^{\text {st }}$ Review Result: August 04, 2021; $2^{\text {nd }}$ Review Result: September 18, 2021 Accepted: October 31, 2021 
핵심어: 인쇄공익광고, 표제문, 설득 전략, 종결 표현

\section{1. 서론}

이 연구는 1981년부터 2021년까지 이루어진 인쇄 공익광고의 표제문에 나타난 종결 표현을 분석하여, 공익광고에서는 어떤 표현을 활용하여 사회 구성원에게 메시지를 전달하며 설득하고 있는지 설득 전략의 측면에서 살펴보는 것이 목적이다. 공익광고는 한 사회에서 공통의 사회적 목적을 달성하기 위한 일종의 의사소통의 수단이다. 그래서 공익광고에는 공공의 추구하는 이익 획득의 방법, 사회적인 문제 요소를 지적하고 이에 관한 최선의 해결 방안을 제시한다. 단순히 현재 무엇이 문제가 되고 있으며, 문제를 해결하기 위한 방법도 제안한다. 더 나아가 문제 해결을 위해 사회 구성원의 적극적인 참여와 실천을 요구하며, 사회적으로 바람직한 행동이 무엇인가 하는 정보를 제공하고 더불어 실천의 결과까지 제시한다[1]. 따라서 공익광고에는 구체적인 메시지가 포함되어 있으며, 구성원이 이 메시지에 공감하고, 바람직한 방향으로 함께 실천해 주기를 설득하고 있다.

의사소통의 상황에서 상대방을 설득하기 위해서는 메시지를 정확하게 전달하는 것도 중요하지만 상대방이 이에 공감하게 하고 더불어 화자가 원하는 행동이 무엇인지를 알 수 있도록 해야 한다. 설득이라는 것은 화자 자신이 옳다고 믿거나 자신이 바라는 것을 상대방에게 납득시키고 그 과정에서 상대방의 태도나 행동에 영향을 끼치어 결과적으로 자신이 원하는 방향으로 상대방을 변화시키려는 목적을 가지고 있는 말하기 방법이기 때문이다[2]. 그래서 공익광고에서도 어떻게 표현하는가가 매우 중요하다. 특히 설득하는 말은 상대방에게 요구하는 것이 포함되어 있기 때문에 인간관계라는 부분에도 주의를 기울여야 한다. 공익광고에서와같이, 대상이 특정되지 않은 사회 구성원 전체인 경우에는 표현 방법에 더욱 주의가 필요하다. 공익광고는 대면 의사소통 방법도 아니고, 다수의 구성원을 대상으로 이루어지기 때문에 설득에 유용한 언어적 표현을 활용할 수 있어야 한다. 상대방의 체면은 상하지 않으면서 동의를 얻어내고 목적하는 행동으로의 변화를 일으키며, 나아가 눈에 보이지 않는 신념이나 이념까지도 동화시키는 것을 성공하려면 사회 구성원의 공감을 얻을 수 있는 표현 방법을 활용해야 하기 때문이다.

지금까지 공익광고에 대해 다룬 연구를 살펴보면 주로 광고에 사용된 언어 표현에 나타난 설득적인 요소에 대해 다루고 있다. 정윤희(2006)에서는 설득에 사용된 전략적 어휘, 특히 인칭 대명사와 생략 현상을 살피고 있으며[3], 전정미(2007)에서는 설득의 요소를 화자, 청자, 메시지 중심으로 나누어 설득은 화자가 원하는 특정한 행동이 청자에 의해 나타나기를 기대하는 목표를 가진 화행으로 설명하였다[2]. 또한 장혜연(2011)에서는 의사소통의 측면에서 공익광고에 나타난 설득의 언어적 표현 기법[4], 최숙이 외(2011)는 전정미(2007)에서 제시한 설득의 요소를 바탕으로 설득 과정에서 장애가 나타날 때에 이를 극복할 수 있는 방법으로 청자에 대한 배려를 제안하였다[5]. 한은주(2011)에서는 공익광고의 주제에 따라 화행의 양상이 각각 어떻게 나타나는지를 보고 전달 메시지에 따라 선호하는 화행의 양상을 제시하였고[6], 전정미(2014)에서는 인쇄 공익광고에서의 표제와 슬로건에 나타난 화행의 실현 양상에 대해 분석하였다[7]. 이상의 선행연구를 통해 확인할 수 있는 요소는 공익광고가 비록 대면의 상황도 아니고 한정된 주제에 관한 내용을 다루고 있음에도 불구하고, 사회 
구성원과 소통하는 하나의 의사소통 방식이라는 점이다. 공익광고에서는 메시지를 전달하는 주체가 화자의 기능을 하고 있으며 청자는 사회구성원, 메시지는 주제를 포함한 광고 텍스트 자체이다. 정부나 공공기관 등 메시지 전달의 주체가 공공의 이익을 위해 구성원과 어떤 방법으로 소통하고 있는지에 대해 살펴보는 것은 다수의 구성원에게 가장 효율적인 설득 전략이 무엇인지 확인할 방법이 될 수 있을 것이다. 또한 특정 주제를 가진 메시지를 전달할 때, 활용되는 표현방식도 살필 수 있을 것이다. 따라서 이 연구에서는 전정미(2014)의 분석 틀을 토대로, 공익광고에서는 구성원들을 설득하기 위해 전략적으로 어떤 종결 표현을 사용하는지 확인하고자 한다.

\section{2. 공익광고의 특성과 언어 표현}

\section{1 공익광고의 주제별 분포}

역사적으로 공공 광고의 시작은 미국이나 영국 등의 사례에서와같이, 전쟁 중에 국민의 사기 앙양이나 통일체 의식을 고취하여 국가적 위기를 극복하기 위해 정부에서 시행한 일련의 캠페인 활동이다. 그러나 그 후에는 인류가 직면하고 있는 각종 사회문제, 부조리 해결이라는 문제에 대해 광고라는 가장 현대적이고 설득력이 뛰어난 수단을 통해 해결하고자 하는 시도로 자리매김하였고, 여기에 공익광고의 가장 큰 의의가 있다고 할 수 있다. 우리나라에서는 방송광고진흥공사에서 1981년 9월 ‘방송광고향상자문위원회' 를 구성하고, 공익광고의 연간 및 월간 주제의 선정, 방송광고의 홍보대책 수립, 방송광고산업의 과학화, 전문화를 위한 기반조성, 공공 광고의 도입 및 정책을 위한 방안을 모색하게 되었고, 12 월 5 일 $\mathrm{KBS}-2 \mathrm{TV}$ 를 통해 ‘저축으로 풍요로운 내일을' 이라는 제목의 공익광고를 처음으로 방송하였다[8].

초기의 공익광고는 국가의 정책을 홍보하는 수단이나 전 국가적 캠페인의 한 방법으로 활용되었는데, 근래에 와서는 개인이 무시되는 공익이 아니라 개인과 사회, 모두에게 필요한 공익적인 요소에 대해 공개적으로 이야기하는 하나의 장으로서 활용되고 있다. 현재 공익광고의 주제를 선정할 때에도 3 개의 과정이 진행되는데, 첫번째로 국내 주요 포털에 게시된 기사나 뉴스를 전량 추출하여, 총 12 개 분야의 키워드를 선정하는 방식으로 사회적인 주요 이슈가 무엇인지 모니터링을 한다. 두번째로는 구조화된 설문지를 기반으로 국민 여론을 모니터링하며, 세번째로 전문가의 의견을 반영하여 주제를 선정하고 있다. 2019년부터는 주제의 적절성, 사회적 기여 및 공익성, 태도/행동/변화, 크리에이티브 등 4개 항목을 평가하여 '광고효과지수' 를 점검하고 있는데, 2019년 11편(73.26점), 2020년 10편(73.42점), 2021년 2편(73.75점)을 분석한 결과, 2019년 2021년에 평가된 총 23편의 광고효과지수는 평균 73.46 점을 나타내고 있다. 또한 방송법상 공익광고는 전체 방송 시간에 대한 일정 비율로 의무 편성하여, 공공의 이익을 증진하는 데에 활용되어야 한다. 이와 같은 내용을 종합해 보면, 공익광고가 인지도나 메시지의 전달력 측면에서 일정한 정도의 효과를 나타내고 있으며, 공공의 복리를 실현하기 위한 구성원과의 의사소통의 수단으로 활용되고 있음을 확인할 수 있다.

한국방송광고진흥공사 공익광고 데이터 광장에 따르면, 공익광고가 처음 시작된 1981년부터 2021년까지 공익광고에서 다룬 주제는 총 412개이다. 1981년에는 총 5 개의 주제가 다루어졌으며, 2021년 현재까지 40년동안 평균 10 개 이상의 주제가 다루어졌다. 총 412개의 주제를 분야별 편수로 분류하면 다음의 [표 1]과 같다[9]. 
[표 1] 공익광고의 주제별 분류(1981 2021)

[Table 1] Category of Public Advertisements by Themes (1981 2021)

\begin{tabular}{|c|c|c|c|c|}
\hline 대주제 & 소주제 & \multicolumn{2}{|c|}{ 건수(개) } & 비율 $(\%)$ \\
\hline 사회공동체 & $\begin{array}{c}\text { 사회화합 } \\
\text { 나눔/ 이웃 } \\
\text { 타인배려/공공매너 } \\
\text { 교통안전 } \\
\text { 안전 } \\
\text { 인터넷 예절 } \\
\text { 언어생활 } \\
\text { 장애인 배려 } \\
\text { 스마트기기 바른 사용 } \\
\text { 부정부패 } \\
\text { 공공질서와 예절 } \\
\text { 저축 }\end{array}$ & $\begin{array}{l}32 \\
32 \\
30 \\
17 \\
15 \\
6 \\
4 \\
4 \\
3 \\
3 \\
2 \\
1\end{array}$ & 149 & 36.17 \\
\hline 경제 사회/기타 & $\begin{array}{c}\text { 국민의식/ 나라사랑 } \\
\text { 국가경제 } \\
\text { 절약/ 소비 } \\
\text { 국가 브랜드 } \\
\text { 선거 } \\
\text { 부정부패 } \\
\text { 통일 } \\
\text { 사회화합 }\end{array}$ & $\begin{array}{c}59 \\
22 \\
16 \\
15 \\
15 \\
4 \\
3 \\
1\end{array}$ & 135 & 32.77 \\
\hline 자연환경 & $\begin{array}{c}\text { 환경보전 } \\
\text { 불조심 } \\
\text { 한강 } \\
\text { 에너지 절약 } \\
\text { 재활용 } \\
\text { 물 } \\
\text { 일회용품 자제 }\end{array}$ & $\begin{array}{c}29 \\
9 \\
8 \\
7 \\
3 \\
3 \\
3 \\
\end{array}$ & 62 & 15.05 \\
\hline 가정/ 청소년 & $\begin{array}{l}\text { 가족/대화 } \\
\text { 청소년 } \\
\text { 폭력예방 } \\
\text { 가족계획 }\end{array}$ & $\begin{array}{c}23 \\
13 \\
7 \\
6\end{array}$ & 49 & 11.89 \\
\hline 공중보건/ 복지 & $\begin{array}{c}\text { 헌혈 } \\
\text { 보건 위생 } \\
\text { 담배/마약 }\end{array}$ & $\begin{array}{l}8 \\
5 \\
4\end{array}$ & 17 & 4.12 \\
\hline & & & & 100 \\
\hline
\end{tabular}

우리나라의 공익광고는 1941년부터 시작한 미국이나 1971년에 시작한 일본보다 시기적으로는 늦었다. 그러나 [표 1]에서 살펴볼 수 있는 바와 같이, 국민의 일상생활과 관련된 구체적인 문제들을 주제로 삼고 있으며, 광고를 활용하여 국민의 의식을 계몽하고 공공성을 제고하는 가치를 지니고 있음을 알 수 있다[10].

\section{2 인쇄 공익광고의 형식 구조}

공익광고는 표현 매체에 따라 텔레비전 공익광고, 바이럴 공익광고, 라디오 공익광고, 인쇄 공익광고, 웹툰 공익광고로 나눌 수 있다. 초기 공익광고에서는 텔레비전과 라디오, 신문이나 잡지 등 인쇄 매체를 주로 활용하였는데, 최근에 와서는 다양화된 
매체 환경에 따라 인터넷을 활용한 공익광고도 늘어나고 있는 추세이다. 이 연구에서는 여러 매체 중에서도 인쇄 공익광고를 분석의 대상으로 삼았는데, 그 이유는 광고가 지면에 나타났을 때, 다른 매체보다 시청각적인 효과가 가장 적게 나타나고 광고 텍스트 전체의 구조적 특성과 언어적 표현 형식을 분명하게 보일 수 있기 때문이다.

일반적인 지면 광고는 언어적 요소와 비언어적 요소로 구성되는데, 언어적인 부분은 '표제문(headline) - 부제문(sub-headline) - 본문(bodycopy) - 슬로건(slogan) 광고주(advertiser)' 로 나타나는 것이 일반적이다. 또한 비언어적인 요소로는 사진이나 그림, 색깔, 글자 크기의 변화 등 시각적인 효과를 나타내는 요소가 사용된다. 언어적인 요소도 내용에 따라 각각의 구성요소 위치가 바뀌거나 부제가 생략되는 등의 변형도 있지만 '표제문-본문-슬로건-광고주' 로 구성되는 것이 가장 일반적이다. 인쇄 공익광고도 다음의 (1)과 같이 일반적인 지면 광고와 동일한 구조를 나타낸다.

(1) 표제문 - 직업에도 성별이 있나요?

본 문 - 혹시 직업으로 성별을 판단하지 않으세요?

세상에는 한 성별만을 위한 직업은 없습니다.

슬로건 - 편견이 아닌 사람을 봐주세요.

광고주 - kobaco 공익광고협의회 (사회화합, 2017)

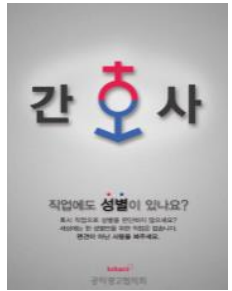

(1)에 제시한 공익광고는 '표제-본문-슬로건-광고주' 의 구조를 갖추고 있다. 표제인 ‘직업에도 성별이 있나요?' 라는 언어적 메시지는 의문문 형식으로 이루어져 있지만 질문이 아니며, 의문의 형식을 통해 구성원들에게 호기심을 유발하여 관심을 집중시키고 있는 것이다. 또한 본문에서는 표제에 나타난 질문에 대해 답을 하는 방식으로 잘못된 편견에 대해 지적하고 있다. 또한 슬로건 부분은 본문보다 진한 글자로 '편견을 갖지 말라는' 구체적이고 핵심적인 메시지를 전달하며 강조하고, 끝으로 광고주에 해당하는

'한국공익광고협의회' 를 표기한다.

이 연구에서는 인쇄 공익광고의 언어 표현 중에서도 표제문에 나타난 표현 방식에 대해 살펴보고자 한다. 그 이유는 표제문이 지면에 올라온 메시지 전체 내용 중에서 가장 눈에 두드러지는 위치에 놓여 있을 뿐만 아니라 잘 보이도록 글자의 모양이나 색채, 크기 등을 특별하게 만들어진 특성을 갖고 있다 김동규(2003: 429)에서는 표제문이 광고문구의 다른 구성요소와 차별화되는 점에 대해 다음의 (2)와 같이 설명하고 있다[7].

(2) 표제문의 기능

ㄱ. 소비자의 주의를 끌 것

ㄴ. 일반 대중 중에서 목표 고객을 골라낼 것

ㄷ. 독자를 표제로 끌어들일 것

ㄹ. 목표 고객에 대한 강력한 편익을 제시할 것

(2)의 설명 중에서 공익광고의 표제문으로서 가장 주요한 기능은 '소비자(청자)의 주의를 끌어낸다' 는 점이다. 청자의 시선을 끌기 위해서는 눈에 두드러지는 효과가 필요하며, 언어적 내용, 글자 모양이나 크기 등을 돋보이게 하여 자연스럽게 본문으로 관심이 이어져 나갈 수 있도록 해야 한다. 또한 목표 고객은 사회 구성원이 되도록 하는 
것이 필요하다. 공익광고의 목표가 공공 이익의 추구라는 점을 고려할 때, 개인의 문제만이 아니라 사회 구성원 전체가 고려해야 하는 전반적인 문제로 이해해야만 설득이 용이하기 때문이다. 공익광고에서 목표를 달성하기 위해서는 언어적 메시지가 청자의 인식 속에서 지속적으로 효과를 발휘할 수 있도록 표제를 구성해야 한다[7].

\section{3 화행과 언어 표현}

의사소통의 상황에서 상대방의 메시지를 잘 이해한다는 것은 말해진 것 그 자체가 아니라 메시지 안에 포함되어 있는 의도를 찾아낸다는 것이다. 곧 화행 이론에서 주장하는 것과 같이 말이 가지고 있는 힘을 찾아내는 것이 의사소통의 성공 여부를 결정하는 요소가 되는 것이다. 공익광고에서도 구성원을 위한 설득의 표현이 겉으로 드러난 표현행위가 아니라 그 안에 내포된 수행행위를 찾아 내는 것이 필요하다.

(3) 곤충도감 속 우리 모습 상상해보셨나요? (언어생활, 2017)

자료 (3)은 사람을 비하하며 사용하는 ' 충' 을 활용한 언어 생활의 문제를 다루고 있는 2017년도의 공익광고 표제문이다. 문장의 종결 방식은 의문문이지만 수행행위는 다른 사람을 비하하는 언어표현을 사용하지 말라는 지시행위가 포함되어 있다. 공익광고 텍스트에는 사회 구성원을 설득하려는 목적을 가지고 있기 때문에 목표로 하는 특정 행위를 지시한다. 공익광고에서의 화자는 정부나 공공기관 등 공공성을 가진 주체이고, 청자는 사회 구성원이다. 비록 공익광고에서 전달하려는 메시지가 비록 공공성을 가진다고 해도 표제문에 \{명령하다, 지시하다\} 등의 수행동사가 직접적으로 사용되는 경우는 극히 드물다. 그 이유는 청자의 역할을 하는 구성원을 대상으로 설득할 때에 수행동사를 직접적으로 사용하기보다는 특정 행동을 수행할 것을 제안하는 방식의 간접적인 표현을 사용하여 강제성을 약화시킨다. 곧 명령문의 형태가 아니라 서술이나 의문의 표현을 통해 전략적으로 설득하고 있는 것이다. 서술문이나 의문문의 수행력은 명령문과 동일하게 작용할 수 있기 때문에 지시행위로서의 기능을 할 수 있는 것이다. 따라서 이 연구에서는 표제문에 나타난 화행의 표현 양상이 설득에 어떻게 활용되고 있는지 살펴보기 위하여 먼저 표현행위에 해당하는 문장 종결방식을 확인하고자 한다. 공익광고에서 전달하고자 하는 '지시행위' 가 어떤 양상으로 나타나는지 살펴보면 설득을 위해 활용되는 다양한 언어적 표현에 대해 확인할 수 있을 것이다.

\section{3. 표제문의 종결 표현과 설득 양상}

이 연구에서는 표제문의 종결 표현에 대해 살펴보기 위하여, 가장 높은 빈도로 나타난 '사회공동체' 에 속하는 12 개의 소주제를 다룬 인쇄 공익광고에 대해 살펴보았다. 우리나라의 공익광고는 1981년부터 시작되었지만, 인쇄 공익광고는 1983년부터 시작되었고, ' 사회공동체' 라는 대분류에 속하는 인쇄 광고 중에서는 ' 나눔/ 이웃' 에 속하는 1984년 ‘마음의 창을 엽시다' 라는 표제문을 가진 광고가 가장 오래된 것이다. 또한 인쇄 공익광고에서는 [표 1]에 제시한 12개의 소주제 중에서 '부정부패, 공공질서와 예절, 저축' 에 관한 것은 나타나지 않았고, '다문화사회, 외모지상주의, 불법 다운로드, 유기견, 양성평등 등의 세부 주제의 광고를 '기타' 로 분류하여 제시하고 있다. 이 연구에서는 '사회공동체' 아래 분류된 10개의 소주제(사회화합, 
나눔/이웃, 타인 배려, 교통안전, 안전, 인터넷 예절, 언어생활, 장애인 배려, 스마트기기, 기타)로 분류된 178 개의 인쇄 공익광고 표제문(중복 포함) 전체를 대상으로 삼아, 자료의 분포와 종결 표현 양상을 양적, 질적으로 분석하였다.

\section{1 표제문의 종결 표현 사용 양상}

표제문은 전달하고자 하는 메시지를 뚜렷하게 하는 부분이기 때문에 다른 구성요소에 비해 상대적으로 주목받는 위치에 놓인다. 178 개의 표제문에 나타난 종결 표현은 종결형과 비종결형의 두 유형으로 나누어진다. 종결형은 자료 (4 ᄀ , ᄂ)과 같이 표제문에 문장의 종결어미가 분명하게 나타난 것이고, 비종결형은 (4 ᄃ ㅂ)에서와 같이 명사, 명사와 조사의 결합, 부사, 연결어미 등으로 종결어미 없이 표제문이 마무리된 유형이다.

(4) ㄱ. 당신이 오늘도 밟은 이것은 누군가의 '눈' 입니다. (장애인 배려, 2020)

ᄂ. '다루기 쉽다', 혹시 이런 생각을 하셨습니까? (타인 배려, 2020)

ᄃ. 아이들은 절대 못 맞추는 문제 (사회화합, 2015)

ㄹ. 육아부담 육아휴직 동등하게 (나눔/이웃, 2019)

ㅁ. 별이 취하는 밤에 (교통 안전, 2018)

ㅂ. . 조금만 바꾸면 (타인 배려, 2006)

인쇄 공익광고의 표제문을 종결형과 비종결형으로 분류하면, 종결형은 모두 $74.16 \%$ (132개)이고, 비종결형은 $25.84 \%$ (46개)이다. 종결형의 전달 방식은 서술형 $(71.97 \%)>$ 의문형(19.7\%) > 명령형(8.3\%)의 순서로 나타났고, 분석 자료로 삼은 표제문에 청유형이나 감탄형은 나타나지 않았다. 종결 표현의 구체적인 양상은 다음의 [표 2]와 같다.

[표 2] 표제문의 종결 표현 분포

[Table 2] Frequently Used Final Ending Forms in Headlinges

\begin{tabular}{|c|c|c|c|c|c|c|c|c|c|}
\hline \multirow{2}{*}{ 종결 유형 } & \multicolumn{4}{|c|}{ 종결형 } & \multicolumn{5}{|c|}{ 비종결형 } \\
\cline { 2 - 10 } & 서술형 & 의문형 & 명령형 & 소계 & 명사 & 명사+조사 & 부사 & 연결어미 & 소계 \\
\hline 빈도(개) & 95 & 26 & 11 & 132 & 35 & 5 & 1 & 5 & 46 \\
\hline 비율(\%) & 71.97 & 19.70 & 8.33 & 100 & 76.08 & 10.87 & 2.17 & 10.87 & 100 \\
\hline
\end{tabular}

표제문의 종결방식의 분포는 종결형이 비종결형보다 월등히 높은 빈도로 나타난다. 문장의 종결방식은 언어내용을 전달하는 과정에서 화자가 청자에 대해 어떤 태도를 가지는가를 보여주는 문법범주이며, 대표적으로 서술법, 의문법, 명령법, 청유법으로 나뉜다[11]. 표제문에 비종결형보다 종결형이 더 높은 빈도로 실현되는 것은 종결형으로 메시지를 전달하면 화자의 의향이 분명하게 포함될 수 있기 때문이다. 문장의 종결어미에는 청자 높임이 동시에 나타난다. 그 이유는 종결어미를 통해 청자가 되는 사회 구성원에게 화자의 의향을 실현하기 위해서이다. 특히 서술형 어미를 사용하는 것은 화자가 주제에 대해 비교적 객관적인 입장을 취하고 있음을 드러내는 것이고, 
의문형 어미를 사용한 것도 대답을 요구하는 것은 아니다. 오히려 메시지 내용을 강조하여 한 번 더 확인하려는 방법이며, 전달하려는 주제에 대한 주의집중의 요소를 실현하는 것이다. 또한 청유형 어미보다 명령형 어미를 선호하는 것은 특정 행동을 요구함으로써 사회 구성원에게 구체적인 영향력을 미치려는 의도가 강하게 나타나기 때문이다.

\section{2 표제문의 설득 전략}

종결 표현이 실현된 표제문에는 화자의 의향이 분명하게 드러난다. 이는 공익광고의 목적상 구성원에게 전달하는 메시지에 대한 화자의 의향이 담겨 있는 것으로 해석할 수 있다. 따라서 종결형 표제문을 살펴보면 메시지를 전달하는 화자가 어떤 입장을 가지고 구성원과 의사소통을 하려는지를 확인할 수 있다.

서술형 어미는 화자가 청자에게 요구하는 것이 없이 사실이나 정보를 전달하는 행위를 나타낸다. 그런데 종결형 표제문 중에서 서술형 어미가 사용되었음에도 불구하고, 구성원에게 요구하는 행위를 내포한 주장이나 단언의 태도가 나타나기도 한다.

(5) ᄀᄀ. 보복 운전은 테러입니다. (교통안전, 2016)

ㄴ. 스마트폰을 열수록 가족 간의 대화는 잠깁니다. (스마트기기, 2013)

(5ㄱ, ᄂ)에서는 보복 운전의 심각성을 '테러' 에 비유하여 표현하고, 스마트폰으로 인한 가족간 대화 단절에 대해 사실을 전달한다. 그런데 여기에는 단순한 사실의 전달이 아니라 그래서 보복운전은 하면 안되고, 가족간의 대화를 좀 더 활성화 하라는 주장이 포함되어 있다. 그런데 이처럼 구체적인 지시 내용은 감추어 두고 표현되는 메시지는 단순하게 사실이나 정보를 서술하는 것처럼 나타내면, 지시적인 행위가 갖는 강제성을 약화할 수 있다.

의문형 어미나 의문 부호(?)가 사용된 표제문에서도 강제성의 약화 현상에 대해 살펴볼 수 있다. 의문형 어미는 상대방에게 대답을 요구하는 것처럼 보이지만 실제로는 청자가 해당 사실에 대해 인지하고 있는지를 확인하고 자신의 행동을 스스로 점검해 보게 한다.

(6) ㄱ. 어떤 강아지가 더 무서울까요? (기타, 2019)

ㄴ. 한번쯤 고민해 보셨습니까? (인터넷예절, 2006)

자료 (6)의 표제문은 모두 질문에 대한 답을 요구하는 것이 아니라 문제가 되는 상황을 인지하고 있는지 확인하고 있다. (6ㄱ)에서는 애완견 목줄 미착용 문제, (6ㄴ)에서는 인터넷에서의 언어사용에 관한 문제 제기를 하고 있지만, 표제문에서는 구성원에게 요구하는 구체적인 행위가 제시되지 않았다. 그러나 표제문을 통해 공익을 위해 필요한 행동이 무엇인지 자각할 수 있도록 한다. 또한 제기된 문제를 해결할 수 있는 방안도 스스로 찾을 수 있도록 유도하면서 특정 행동에 대한 강제성을 약화하고 있다.

서술문이나 의문문과는 달리, 명령형 어미에는 화자가 청자에게 구체적인 행동을 요구하는 의도가 드러나며, 동시에 청자에 대한 높임의 정도가 포함되어 나타난다. 
(7) ᄀ. 삶의 지혜, 찾아보지 말고 찾아 뵈세요. (스마트기기, 2013)

ㄴ. 세상을 보기 전에 주위를 먼저 보십시오. (타인 배려, 1999)

자료 (7)의 표제문에는 모두 청자에게 요구하는 구체적인 행위가 지시되어 있지만 격식성의 측면에서는 차이가 있다. (7그)은 청자 높임의 등급에서 보통 높임의 등급이고 비격식적이지만, (7)은 높임의 등급 중에서 가장 높은 등급이면서 격식성도 갖춘 형태이다. 명령형 어미를 사용하면 요구하는 행위가 명확해져서 설득하고자 하는 메시지의 전달력을 높일 수 있지만 청자의 입장에서는 부담스러운 표현이다. 자료를 살펴보면, (7그)과 같은 유형(9개)이 (7ㄴ)의 유형(2개)보다 더 높은 빈도로 나타난다. 곧 표제문에는 높임의 등급이 높고 격식성을 갖춘 표현보다 높임의 등급이 낮고 비격식적인 어미가 사용됨을 알 수 있다. 이와 같은 양상은 표제문에서 높임의 등급을 낮춤으로써 명령형 어미로 인한 강제성과 공적인 관계라는 점을 약화함으로써 청자가 수용하기 용이하게 하는 설득의 방법으로 활용되는 것이다.

\section{4. 결론}

이 연구에서는 1981년부터 2021년까지 나타난 공익광고 중에서 '사회공동체' 라는 대주제로 분류되는 인쇄 공익광고 178편의 표제문을 대상으로, 어떤 종결 표현이 사용되었는지 그 양상을 살펴보았다. 공익광고에서는 공공의 이익을 추구하고, 문제 해결을 위한 방안을 제안하기 때문에 지시적 메시지를 담고 있다. 따라서 표제문을 통해 지시적인 메시지를 구성원 전체에게 어떻게 전달하고 있는지 살펴보고, 의사소통의 수단으로서 공익광고가 갖는 의의에 대해 확인하였다.

분석 결과, 공익광고 표제문에서 지시적인 메시지를 전달하는 방법으로 활용된 주된 종결 표현은 직접적인 명령문의 형식이 아니라 오히려 서술문이나 의문문과 같이 지시적 내용이 간접적으로 나타나는 표현이다. 또한 문장 안에 나타나는 구체적인 하위 내용도 표현 방식과는 달리 중립적이고 객관적이며, 상황을 전달하는 데에 초점을 맞추고 있으며, 요구하는 행동을 지시하면서도 강제성을 약화하는 방법으로 표현하고 있다. 이를 의사소통의 관점에서 생각해 보면, 인쇄 공익광고가 일상적인 대화와는 전혀 다른 상황에서 사용되는 것이지만 그럼에도 불구하고 여전히 상대방을 배려하고, 상대방의 체면을 세워주는 의사소통의 원리를 지키고 있다는 것을 알 수 있다. Lakoff(1973)에서, 메시지가 명료하면서도 공손성을 지키기 위해서는 강요하지 않고(Don' t impose), 선택할 수 있게(Give options) 하는 방법이 필요하다[12]는 것과 같은 맥락에서 이해될 수 있다.

이 연구는 공익광고 전체를 대상으로 한 것은 아니라 인쇄 공익광고의 표제문으로 한정하였기 때문에, 다른 매체를 활용한 공익광고나 비주얼에 관한 부분은 다루지 않은 한계가 있다. 그러나 메시지를 전달하는 가장 적절한 방식은 매체마다 다를 수 있기 때문에 이 연구의 결과로 나타난 종결 표현의 양상은 인쇄된 지면 광고라는 매체적 특성을 보여줄 수 있다는 점에서 그 의의를 찾을 수 있겠다. 또한 이 연구의 결과로 사회 구성원의 주의를 환기하고 공익을 달성하는 방향으로 행동을 전환시키기 위해, 더 나은 의사소통의 방법을 찾아내는 데에도 조금 더 기여할 수 있는 바탕이 될 것이다. 


\section{5. 감사의 글}

이 논문은 2020년 상명대학교 교내연구비 지원을 받은 연구입니다.

\section{References}

[1] Jeon Jung-mi, A Study of the Persuasion Strategy in Public Service Advertising Text, Korean Language Research, (2012), No.31, pp.261-282. DOI : 10.16876/k1rc.2012..31.261

[2] Jeon Jung-mi, A Study on Aspects of Persuasion Speech Act in Advertising Text, Journal of Korean National Language and Literature, (2007), No.38, pp.31-55. UCI : G704-001823.2007..38.012

[3] Jung Yoonhee, Linguistic Characteristics in TV Public Service Advertisements, Sae-U1 Review, (2006), Vol.18, pp.253278.

[4] Hui-Juan Zhang, A Study of the Mandarin for Public Welfare Advertisements in Print Media, Chungnam National University, Unpublished Master's thesis (2011)

[5] Sook Yee Choi, Jung Min Bsek, A Study of the Strategies in Persuasive Speech, Journal of Speech Communication (JSC), (2011), No.19. pp.359-388. DOI : 10.18625/jsc.2011..19.359

[6] Han Eunju, A Study on Speech Act of the public campaign advertisement, Ewha Womans University, Unpublished Master's thesis (2011)

[7] Jeon Jung-mi, A Study on the Implementation of Speech Acts in the Headlines and Slogans of Public Service in Printed Advertisements, Korean Language Research, (2014), Vol.35. pp.203-229. DOI : 10.16876/klrc.2014..35.203

[8] https://www.kobaco.co.kr/site/main/content/what_public_ad, Jun 19 (2021)

[9] https://psadata.kobaco.co.kr/, Jun 19 (2021)

[10] Byoung Hee Kim, The Results and Perspectives of 30 Years of Public Service Advertising Creative from Theme Changes and Award Achievements, The Korean journal of advertising and public relations, (2012), Vol.14, No.2, pp.242-264. UCI : G704-001035.2012.14.2.001

[11] Jae Il Kwon, Korean Syntax, Minumsa, (2007)

[12] R. Lakoff, The logic of politeness, or minding your P's and Q's, Proceedings of ninth regional meeting of Chicago Linguistic Society, (1973), Vol.9, No,1, pp.292-305. 